\title{
La Simultaneidad en las Novelas de Cortázar
}

La literatura, las palabras, son el modo expresivo más dominado por la secuencia temporal. Sin embargo, durante los últimos cien años ha habido una corriente literaria orientada hacia la presentación de hechos simultáneos. Esta tendencia ha producido una situación paradójica para el lector: mientras él "avanza" por un texto, no progreso temporal sino espacialmente. Describir la aparición de esta técnica en uno o en varios autores sería, quizás, aislar una tradición dentro de una tradición, registrar la presencia de algo que compromete un medio expresivo y que anuncia la creación de otro.

La simultaneidad literaria parece tener sus orígenes en la sátira, ya que se puede generar ironía yuxtaponiendo dos fenómenos totalmente dispares para que se combinen en la mente del lector. La muy comentada escena de la feria en Madame Bovary $(1856)^{1}$ fue, hasta para su autor, un vehículo para parodiar el mundo rural entero, desde la retórica de los politicos hasta la oratoria de Rodolfe mientras seduce a Emma. La incongruencia es siempre la base del humor, y la escena flaubertiana es un ejemplo de cómo la incongruencia puede envolver un mundo entero, cómo la mera yuxtaposición de hechos que ocurren simultáneamente puede llevar a la sátira.

Por otra parte, la escena irtumpe la secuencia lógica de la novela. Las tramas derivan su coherencia del orden cronológico de hechos y de la impresión de causa y efecto que aparece en el fluir de estos hechos. Madame

1 El roncepto de la epecialización literaria y su papel en Flaubert y en la ficción moderna se derivan del ensayo del profesor Joseph Frank "Spatial Form in Modern Literature", publicado primero en The Sewanee Review, Vol. LIII, Number 2 (Spring, 1945); Number 3 (Summer, 1945); Number 4 (Autumn, 1945), y recopilado en una colección de ensayos del profesor Frank, The IVidening Gyre (New Brunswick, 1963), 3.60. El Tristram Sbandy (1760) de Lawrence Sterne, con su negación del concepto de trama, o Melmoth the Wanderer (1820) de Charles Maturin, con sus cicentos dentro de cuentos, podrían también servir como ejemplos del efecto de la simultaneidad en la estructura de la novela. 
Bovary tiene una trama típica de la novela del siglo xix porque en la resolución de su drama hay resonancias históricas además de personales; es decir, hay una relación íntima entre las posturas sociales o intelectuales asumidas por los personajes y los conflictos sociales e intelectuales de la época. Pero la escena de la feria rechaza por un momento el juego dialéctico de la historia para concentrarse en la substancia no diferenciada de la historia: el tiempo. El efecto de esta escena particular no es, sin embargo, temporal sino espacial. Es una pintura en palabras, un momento que parece tener tres dimensiones. Para Gotthold Ephraim Lessing, cuyo Laoconte trata precisamente de limitar la descripción en palabras y la narración en las artes plásticas, la escena flaubertiana de la feria habría sido una violación del territorio del arte verbal:

Si es verdad que la pintura emplea signos o métodos de imitación totalmente distintos a los de la poesía -ésta empleando sonidos articulados en el tiempo y aquélla formas y colores en el espacio,y si los signos tienen indudablemente que estar en una relación conveniente con la cosa significada, entonces signos que están puestos en una fila sólo pueden representar objetos que existen en una fila, o cuyas partes existen así, mientras que signos consecutivos sólo pueden expresar objetos que se suceden o cuyas partes se suceden en el tiempo. ${ }^{2}$

Las objeciones de Lessing aparentemente no influyeron en Flaubert que escribió Madame Bovary unos noventa años después del Laoconte, pero su concepto de la afinidad entre las palabras y el tiempo puede interesar a los lectores de la narrativa hispanoamericana actual.

Los orígenes de esta manifestación reciente de la simultaneidad literaria se encuentran en la técnica de Flaubert (que se quedó en esto: una técnica) sino en la estética de varios de los movimientos de vanguardia de la primera fase de este siglo. Los futuristas, ${ }^{3}$ primero, trataron de expresar lo que consideraban la esencia de la vida moderna, un modo de ser en que alguien podría estar expuesto sinultáneamente a varias experiencias. Esta multiplicidad, según los futuristas, sólo podría comunicarse

2 Gotthold Ephraim Lessing, Laokoon oder Über die Grenzen der Malerei und Poesie (1776), Gesammelte Werke, II (München, 1969), 875.

a Un estudio nuy interesante sobre la simultaneidad en la literatura de vanguardia es el de Pär Bergman, "Modernalotria" et "Simultaneitä" Recherches sur deux tendenies dans l'avantgarde littérairé en Italie et en France à la veille de la première guerre mondiale (Uppsala, 1962). 
si se destruyera la sintaxis y si se representaran fonéticamente los sonidos de la "edad de las máquinas":

Otros poetas, en particular Ezra Pound y T. S. Eliot, quisieron crear cbras de las que el lector derivaría una nación de totalidad sólo después de "experimentar" todas las partes de la obra. No trataban, como los futuristas, de reproducir la vida del siglo $\mathrm{xx}$, sino que, siguiendo a los simbolistas, intentaban trascender los nexos tradicionales entre palabras y narración. Sus poemas consistían en narraciones interrumpidas, anécdotas empezadas, abandonadas, reiniciadas y finalmente terminadas. Así, la obra resultaba incomprensible en sus partes y comprensible sólo como una totalidad. Como ha dicho el profesor Joseph Frank:

Aesthetic form in modern poetry, is based on a space-logic that demands a complete reoricntation in the reader's attitude toward language. Since the primary reference of any word-group is to something inside the poem itself, language in modern poetry is really reflexive. The meaning-relationship is completed only by the simultaneous perception in space of word-groups that have no comprehensible relation to each other when read consecutively in time. Instead of the instinctive and immediate reference of words and word-groups to the objects or events they symbolize and the construction of meaning from the sequence of these references, modern poetry asks its readers to suspend the process of individual reference temporarily until the entire pattern of internal references can be apprehended as a unity. (Frank, 13)

Fue en la poesía donde primero se experimentó con la simultaneidad en gran escala, a pesar del uso por parte de Flaubert de la yuxtaposición satírica. Sin embargo, los experimentos de Flaubert y los de Eliot indicaban la posible incorporación de lo simultáneo en la novela del siglo $\mathrm{xx}$, como pasa en el Ulises (1922) de James Joyce, donde la técnica se convierte en estética. Lo que Flaubert hace en una escena, Joyce lo hace en una obra entera (aunque sus intenciones no son del todo satíricas): "As a result, the reader is forced to read Ulysses in exactly the same manner as he reads modern poetry, that is, by continually fitting fragments togheter and keeping allusions in mind until, by reflexive reference, he can link them to their complements. (Frank, 18) La relación entre las partes y el todo en el objeto estético se trastorna: Las partes ya no componen la totalidad, sino que el conjunto sirve de apología para cada parte individual. 
Las declaraciones de Lessing sobre los límites de las artes verbales y plásticas no son necesariamente importantes en una considetación de la literatura moderna, pero lo que dicen sobre la relación entre secuencia cronológica y narración sí puede aplicarse al futuro de la novela. La obra de Flaubert representa el apogeo de cierta clase de novela, pero contiene el germen de una actitud que concierne totalmente a la estructura temporal de la novela. Este germen, sin embargo, no es más que una desviación momentánea para Flaubert, cuyo interés principal es el comportamiento humano dentro de un marco histórico.

Las preocupaciones de épocas pasadas, aunque éstas disten apenas cien años del momento actual, contrastan irónicamente con las actuales. La palabra "novela", que la historia literaria nos ha dado, debe limitarse a la descripción de aquellas obras que reproducen la dialéctica de los elementos de un período histórico específico junto con sus habitantes - todo en una manera verosímil. La otra dimensión, esta espacialización de la literatura, que desde el simbolismo ha ido infiltrándose en la narrativa de Occidente, y más recientemente en el cine, ${ }^{4}$ parece anunciar una nueva edad en nuestras letras, una edad en que nociones de cambio, evolución, dialéctica y progreso serán reemplazadas por la expresión de un pensamiento o concepto inmutable.

Cuando Julio Cortázar publicó Los premios en 1960, dio su primer paso hacia la incorporación en gran escala de la técnica de la especialización en su literatura. ${ }^{5}$ Sus amigos, como él mismo nota en una posdata a la obra, se quejaban de uno de sus juegos narrativos, los soliloquios de Persio, porque éstos desconcertaban el progreso de la trama. Tales pasajes, como dice Cortázar en la misma nota, son como "una suerte de supervisión de lo que se iba urdiendo o desatando a bordo". (Nota) Hacen esto permitiendo que el narrador medite "en voz alta" sobre las varias etapas de la trama. Pero la clase de digresión que constituyen está en conflicto con el sistema cerrado de la novela y en realidad interrumpe la secuencia temporal de la obra. Forman una obra dentro de una obra, un comentario tan interesante como la materia que comentan. La novela termina con la dispersión de los personajes, la restauración de la vida "normal;" en cambio, los soliloquios terminan de una manera muy diferente, en una nota de descanso, como si una verdadera catarsis hubiera

4 Especificamente L'année dernière à Marienbad de Alain Robbe-Grillet.

5 Nótese que el personaje Johnny Carter en "El perseguidor", Las armas secresas (Buenos Aires, 1959) también habla de su experiencia de la simultaneidad al describir la compresión de muchas experiencias, del pasado y del presente, cuando está en el metro (112-115). Esta sensación se asemeja a la ubicuidad que Horacio Oliveira menciora en Rayzela (Buenos Aires, 1963), 407. 
ocurrido, como si en la torpe revolución que describió, el autor-narrador hubiera visto algo que le diera la esperanza y la renovación espiritual que son las etapas finales de la tragedia o la comedia tradicionales. No fue, sin embargo, un movimiento hacia adelante el que produjo esta catarsis; más bien fue una serie de ensueños en que el narrador podía saltar desde una escena potencial (imaginaria) hacia una síntesis de posibilidad y realidad. En este movimiento lateral Cortázar demuestra su primer uso novelesco de la espacialización además de su necesidad de escribir el drama abstracto del romance ${ }^{6}$ basado ambiguamente en la realidad histórica.

En sus cuentos, Cortázar siempre había mantenido la verosimilitud usando un tipo especial de lenguaje literario y escenarios especificos, reales. Éstos siempre formaban un contraste irónico con las acciones que allí se describen. Igualmente en Los premios: La "verdadera" Argentina de la época post-peronista queda atrás cuando el "Malcolm" baja el río, y una Argentina que "puede ser" se cristaliza alrededor de varios elementos de la burguesía. Esta "nueva" Argentina también se desarrolla en términos espaciales y no temporales: Para hacer entrar a sus personajes en una nueva realidad, Cortázar les hace tener experiencias simultáneas. El proceso empieza en el London Café, donde los premiados se reúnen antes de ir al barco. Todos los personajes principales tienen que estar presentes, y todos tienen que escuchar a Humberto Roland cantar "Muñeca brava", aunque el anuncio de que va a cantar y el acto de cantar ocurren en distintos capítulos, como si el tiempo se detuviera para dejar aparecer a más personajes.

La espacialización, una consideración de las muchas facetas del mismo momento o idea, es uno de los rasgos fundamentales de las narraciones extensas de Cortázar. Existen tramas, los personajes cambian, el tiempo es un factor, pero no es la intención de Cortázar escribir una "historia". En cambio, quiere que cada una de sus obras sea un signo, un objeto significante que se deje entender como una idea y no como una experiencia temporal. La trama de L'Immoraliste (1921), de Gide, y la trama de Voyage au bout de la nuit (1932), de Céline, trazan una ruta más o menos circular, pero ambas obras llevan a sus respectivos protagonistas por una serie de experiencias que a su vez nos conducen a ciertas conclusiones. Las tramas de Cortázar, en Los premios y en sus otras obras largas, no hacen esto. Los personajes no son cambiados esencialmente por sus experiencias novelescas: Al final de Los premios vuelven a Buenos Aires y a sus vidas pasadas, sin ninguna alteración.

Este término aparece en Anatomy of Criticism (Princeton, 1957), 304-308, de Northrop Frye. 
Lo que acontece a bordo del "Malcolm" es algo que sólo Persio, el autor-narrador y el lector pueden comprender. Los actores, menos Medrano cuya iluminación le cuesta la vida, se quedan enmarañados en grado mayor o menor en sus dramas personales y no pueden captar el significado total del viaje. El progreso - aun dentro de los límites de los ritos de iniciación, los rituales de combate con lo desconocido que componen la acción en el barco- carece de importancia porque los personajes, como vidas individuales, no tienen interés ( $\mathrm{y}$ este hecho nos indica el significado de la cita de Dostoievski sobre los personajes vulgares que abre la obra). No fue una fantasía literaria lo que causó que Cortázar transformara a un dentista (Medrano) en un héroe trágico y víctima sacrificial, sino un deseo de mostrar que las vidas novelescas de sus personajes son obstáculos en el camino de la auto-realización. Como siempre en la literatura de Cortázar, es el lector el que es de primera importancia, y cualquier cambio que el autor pueda realizar en él es mucho más importante que los cambios en los personajes.

Esta intención de crear una obra metafórica, significante como experiencia o idea y no como anécdota, se repite en Rayuela (1963). Allí la obra presentada al lector, un objeto literario que contiene su propia teoría estética, pretende cambiar las opiniones del lector sobre la relación entre arte y vida. Si las partes de Rayuela pueden articularse en un conjunto significante, y esto es al parecer la creencia del autor, entonces hay que entender el libro como una teoría de la literatura ilustrada, el producto y la propaganda. Necesariamente entonces, la mezcla de los Capítulos 1.56 y los "Capítulos prescindibles" es otro experimento con la espacialización de la literatura narrativa. Si se entiende que los Capítulos $1-56$ son una novela, entonces los otros capítulos, en particular los que no son escenas novelescas, sirven para los mismos fines formales que los soliloquios de Persio. El fluir temporal se interrumpe, la trama se estorba, la fibra histórica de la novela se deshace y el relleno estético que engendró la obra entra en su mundo hermético, cerrado. Otra vez, las partes en sí mismas no tienen significado. Leer sólo los Captíulos 1.56 es no leer Rayuela como totalidad, y leer los "Capítulos prescindibles" sin la novela es imposible: Leídos juntos forman un símbolo o signo algo corpulento, una totalidad que se analiza a sí misma y pretende ser entendida en un instante. La lectura de la obra entera debe culminar en una unión casi mística entre el lector y la sensibilidad del artista.

Quizá. De todas maneras, el impulso de expresar hechos simultáneos también ocurre en la sección novelesca de Rayuela. En la secuencia Capítulo 19 a Capitulo 27, dos actividades separadas se describen: Horacio 
Oliveira paseándose, yendo a un concierto y conociendo a Berthe Trépat, y la Maga hablando con Ossip Gregorovius en un cuarto. El contraste entre las escenas no es el mismo contraste que logra Dostoievski en Crimen y castigo entre escenas interiores y exteriores; más bien le permite al lector ver tres visiones de Horacio: una, de Horacio mismo; otra, Horacio a través de Berthe Trépat (como Cortázar, alguien que mezcla formas dispares de expresión) que, como Horacio, rechaza la piedad y, la tercera, Horacio como Ossip, su gemelo opuesto. Aparte de ser un recurso de la trama, las escenas simultáneas no tienen ninguna función verdaderamente novelística ya que no añaden complicaciones a la trama original; sencillamente refuerzan lo que el lector ya sabe del protagonista y desembocan en una escena con la que no tienen ningún nexo lógico, causal.

Entonces, la relación entre estos retratos simultáneos de Horacio, la Maga y Ossip y el resto de la linea narrativa de los Capítulos 1-56 no es dramática sino acumulativa. Conscientemente se evitan drama y melodrama en la novela, y la muerte de Rocamadour, la única crisis verdadera además del Capítulo 56, está al final de una escena tan larga y tan complicada que es más bien un descanso que una culminación. No hay una descripción de los momentos finales de Horacio en París, y la ruptura con sus amigos es sencillamente contada por otro personaje. La trama, sin embargo, lleva a Horacio inevitablemente a Buenos Aires, al sanatorio y, finalmente, a la experiencia contenida en el Capítulo 56. Esta escena es ciertamente una crisis, pero exactamente qué es la crisis y cuáles son sus resultados no está claro. Es una crisis falsa, porque el lector no sabe más del destino de Horacio Oliveira al final de la escena de lo que sabe al principio.

Este modo lateral de expresión artística se revela más claramente en la obra total. La trama esquelética de los Capítulos $1-56$ se interrumpe, se pierde en digresiones y a veces desaparece para que otros asuntos puedan explorarse. Se menciona a Morelli en los Capítulos 1-56, pero en el texto completo llega a ser un personaje real además del "autor" de una serie de conceptos estéticos. Si en la novela dentro de Rayuela el drama de Horacio se presenta como una experiencia no-dramática, en la obra total se transforma en el pretexto para una experiencia artística mucho más amplia. Se rechaza casi totalmente el drama y el único elemento novelesco retenido es la ya tenue estructura temporal. Irónicamente, al final de la lectura, el lector se encuentra oscilando entre dos pseudo-finales, una parodia más de los conceptos tradicionales de comienzos, desarrollos $y$ fines. 
Cortázar continúa en 62 modelos para armar su batalla recurrente con las tramas. El libro, sin embargo, no es la literatura aleatoria que $R a$ yuela, con sus saltos físicos dentro de un mismo texto, habría prometido. En cambio, es una vuelta hacia la escritura atemporal que ocurre en el nouveau roman francés, en particular en las obras de Alain Robbe-Grillet. Pero no es de ninguna manera una nueva novela en español, aunque se apropia la metodología de Robbe-Grillet y de algunos de los precursores de Robbe-Grillet, específicamente Raymond Roussel. Cortázar ha dicho ${ }^{7}$ que el uso por Roussel de homónimos y sus juegos con los varios significados de una misma palabra le han influido, notablemente en los soliloquios de Persio en Los premios, pero nunca intentó basar una obra entera en las permutaciones de algunas palabras. 62, entonces, es la culminación de dos de las preocupaciones de Cortázar: la creación de una obra exenta de psicología y la erradicación del concepto de la literatura narrativa como historia.

Tandis que, dans le récit moderne, on dirait que le temps se trouve coupé de sa temporalité. Il ne coule plus. Il n'accomplit plus rien. Et c'est sans doute ce qui explique cette déception qui suit la lecture d'un libre d'aujourd'hui, ou la représentation d'un film. Autant il y avait quelque chose de satisfaisant dans un "destin", même tragique, autant les plus belles des oeuvres contemporaines nous laissent vides, décontenancés. Non seulement elles ne prétendent à aucune autre réalité que celle de la lecture, ou du spectacle, mais encore elles semblent toujours en train de se contester, de se mettre en doute elles-mêmes à mesure qu'elles se construisent. Ici l'espace détruit le temps, et le temps sabote l'espace. La description piétine, se contredit, tourne en rond. L'instant nie la continuité. ${ }^{8}$

Robbe-Grillet elocuentemente describe la situación de la literatura nàrrativa moderna, y nos vuelve otra vez a Lessing. Lessing queda obsoleto a causa de las intenciones de Robbe-Grillet ya que el escritor ha dejado de tratar de escribir una pintura en palabras, y está simplemente tratando de encantar al lector con su sonido. El concepto de Lessing de que las palabras son el único vehículo apto para la narración parece también obsoleto ya que la anécdota no es de ninguna importancia.

7 Julio Cortázar, La vuelta al día en ochenta mundos (Buenos Aires y México, 1967), 81.

8 Alain Robbe-Grillet, "Temps et description dans le récit d'aujourd'hui", Pour un nouveau roman (Paris 1963), 168. 
Es una nota estimulante, Héctor Schmucler, uno de los críticos más sensitivos de Cortázar, dice de 62 :

2. Dicho de manera escandalosa, 62 debe leerse de château a château en la interioridad del significado; no de sujeto a predicado. Las "razones", la lógica de su trama, nada tienen que ver con las determinaciones psicológicas habituales que reflejan los mecanismos del pensamiento de occidente. Juan compra un libro porque antes o después (antes y después) —en la intemporalidad del signo- exis. ten la condesa y el comensal gordo.

En este campo de lectura, los personajes viven en existencia que repite los gestos de lo cotidiano; pero el texto permanece ajeno a sus relaciones y sugiere un orden diferente. Orden de funciones que se repiten, huecos que se llenan en una estructura a-histórica. ${ }^{9}$

Es decir, 62 se basa en palabras, no en un cuento. La primera frase: "Quisiera un castillo sangriento,' había dicho el comensal gordo." (62, 9) o no tiene significado o es una imagen vagamente surrealista hasta que el lector encuentre que la frase se repite en francés un párrafo adelante. Entonces, se sabe que "château" es un modo parisino de referirse a un filet chateaubriand y que saignant significa medio crudo, está en condiciones de comprender los movimientos oscuros que dan forma a la novela. El libro que el personaje Juan lee o no lee es otro "château" porque es el 6,810,000 litres d'eau par seconde de Michel Butor en que se utilizan las observaciones de Chateaubriand sobre las cataratas del Niágara. $\mathrm{Y}$ así. Los "cuentos" novelescos que ocurren en 62, los cuentos de amor y frustración, son por lo tanto el resultado de una serie inicial de asociaciones de palabras con las cuales no tienen ninguna relación. Sin embargo, están allí, y su presencia discontinua interesa al lector de alguna manera, aunque sea solamente porque permiten la formación (quizás falsa) de nexos temporales entre escenas totalmente aisladas. No importa que la estructura temporal quede mutilada, que, al final, el lector se encuentre al principio, porque esta sombra de la narrativa tradicional le facilita la composición de 62 , la construcción de un todo estético.

El método de Alain Robbe-Grillet es totalmente ajeno al de Cortázar porque aquel deja que los objetos mismos sugieran un cuento. No tiene que incluir los soportes temporales de Cortázar.

" Héctor Schmucler, "Notas para una lectura de Cortázar", Los libros (Buenos Aires, agosto de 1969) 11. 
Le fouet de cuir, dans la vitrine d'un sellier parisien, les seins exposés des mannequins de cire, une affiche de spectacle, la réclame pour des jarretelles ou pour un parfum, deux lèvres humides, disjointes, un bracelet de fer, un collier à chien, dressent autour de moi leur décor insistant, provocateur. Un simple lit à colonnes, une cordelette, le bout brûlant d'un cigare, m'acompagnent pendant des heures, au hasard des voyages, pendant des jours. ${ }^{10}$

Estos elementos no son, como en Cortázar, los pretextos para un relato: Son el relato. Cortázar ha decidido emular el método de Raymond Roussel: "Je choisissais deux mots presque semblables (faisant penser aux métagrammes). Par example billard et pillard. Puis j'y ajoutais des mots pareils mais pris dans deux sens différents, et j'obtenais ainsi deux phrases presque identiques." 11 Pero Cortázar ha limitado esta técnica a un paso inicial, el "château," y no la ha seguido hasta el grado de Roussel.

62 es también comprensible como drama; el lector no se da cuenta de que lo que está leyendo no tiene significado como anécdota. Los cuentos de amor, las viñetas cómicas en Londres, todos existen por su propia cuenta, ajenos al juego del "château" y a la técnica de la espacialización. Parece que Cortázar sí ha dado varios pasos hacia la alteración de su técnica narrativa, pero que una vez más ha dejado que su afinidad por la anécdota - ¿la maldición que persigue a todo cuentista? - supere su deseo de crear un texto no psicológico, arreglado espacialmente.

La espacialización en la literatura moderna ha producido un conflicto entre estilos narrativos, parecido a la tensión entre estilos cultos y llanos en el Renacimiento. Notar la manifestación de este fenómeno en las obras de Julio Cortázar y la lucha entre él y la propensión del autor a la anécdota no es hacer más que trazar los nexos entre un escritor y su edad, un primer paso en la indagación de cómo el artista transforma la expresión - de su época en una parte esencial de su propio estilo.

Alfred J. MacAlam

Yale University

10 Alain Robbe-Grillet, La maison de rendez-vous (Paris, 1965), 11-12.

11 Raymond Roussel, Comment 'ja écrit certains de mes livres (Paris, 1963), 11. 